\title{
THE PROBLEM OF THE TOP CELL FOR THE MICROMORPH TANDEM
}

\author{
RAINER PLATZ, J. MEIER, D. FISCHER, S. DUBAIL AND A. SHAH
}

platz@imt.unine.ch; http://www-micromorph.unine.ch

Institut de Microtechnique, Université de Neuchâtel

Rue A.-L. Breguet 2, CH-2000 Neuchâtel, Switzerland

\section{ABSTRACT}

A detailed study of the influence of different materials for the amorphous top cell on the stabilized efficiency of amorphous silicon/microcrystalline silicon ("micromorph") tandem cells is presented. The authors investigate different amorphous i-layer materials which are applied in cells with varying thicknesses. It is shown that it is preferable to optimize the top cell in order to obtain a high current rather than a high voltage.

A simple optical and electrical model is presented which allows one to predict the optimum optical bandgap of the i-layer material of the top cell and to determine its optimum thickness for maximum stabilized efficiency. By means of this model it is shown that the optimum top cell for a total cell current of $26 \mathrm{~mA} / \mathrm{cm}^{2}$ should contain an about $2500 \AA$ thick i-layer with an optical gap $\mathrm{E}_{04} \approx 1.8 \mathrm{eV}$. The model furthermore shows that it is desirable to obtain slightly bottomlimited conditions after degradation in order to maximize the output power.

A stabilized efficiency of $10.7 \%$ for a micromorph tandem cell has been confirmed by an independent measurement (FhG-ISE). Another such cell yields a stabilized efficiency of $11.2 \%$ as measured in our laboratory.

\section{INTRODUCTION}

Microcrystalline silicon $(\mu \mathrm{c}-\mathrm{Si}: \mathrm{H}) \mathrm{p}$-i-n cells [1] have gained a lot of interest in the last 3 years. However, the efficiency of a $\mu \mathrm{c}-\mathrm{Si}: \mathrm{H}$ cell alone is still rather low. Micromorph cells, i.e. $\mathrm{a}-\mathrm{Si}: \mathrm{H} / \mu \mathrm{c}-\mathrm{Si}: \mathrm{H}$ tandems have, in contrast, shown very promising performances $[2,3]$. It, however, turns out that in the micromorph tandem cell the design of the a-Si:H top cell becomes very critical. This is because the top cell produces $2 / 3$ of the total power, while it is at the same time subject to light-induced degradation. As the $\mu \mathrm{c}-\mathrm{Si}: \mathrm{H}$ cell can provide at least $26 \mathrm{~mA} / \mathrm{cm}^{2}$, the top cell current should approach $13 \mathrm{~mA} / \mathrm{cm}^{2}$ without back reflector and at the same time its $\mathrm{V}_{\mathrm{OC}}$ and its stability should be high.

In this paper we propose to determine the top cell i-layer material for the optimum stabilized tandem cell performance. The importance of the top cell for the performance of the micromorph tandem cell has been underestimated so far.

In the first part of this paper we will investigate a series of amorphous i-layer materials, employing $\mathrm{H}_{2}$-dilution and different deposition temperatures; these layers are then incorporated into single junction $\mathrm{p}-\mathrm{i}-\mathrm{n}$ cells with varying thicknesses of the i-layer. An identical $\mu \mathrm{c}-\mathrm{Si}: \mathrm{H}$ bottom cell was then deposited onto each cell of these series of amorphous p-i-n cells. Systematic degradation experiments were performed on both the amorphous $\mathrm{p}-\mathrm{i}-\mathrm{n}$ cells and the micromorph tandem cells, in order to determine the optimum i-layer thickness for each top cell material. All cells presented in this paper have been produced by the VHF glow discharge technique.

In the second part of this paper, we try to work out by semi-empirical modeling of the spectral response and of the I-V-curve of the tandem cell the optimum top cell, i.e. optimum thickness and bandgap energy of the i-layer, in order to obtain a maximum in stabilized efficiency of the tandem cell. Modeling furthermore allows us to predict the influence of current matching on the stabilized output power.

\section{COMPARISON OF DIFFERENT TOP CELL MATERIALS, THICKNESS SERIES}

Since the fabrication of the first micromorph tandem cell there has always been the question persisting which top cell i-layer material and which i-layer thickness would yield the highest 
overall stabilized efficiency. Previously, we had studied several VHF-deposited materials with respect to increasing stabilized efficiencies for purely amorphous single junction and stacked cells [4]. Similar to RFdeposited materials [5,6,7], $\mathrm{H}_{2}$-dilution of the i-layer material was found to result in more stable amorphous stacked cells. There is, however, the problem of the increasing gap under $\mathrm{H}_{2}$-dilution, which is particularly unwelcome in the context of micromorph cells with their high current density levels. Cells from "standard" a-Si:H material, produced without $\mathrm{H}_{2}$-dilution together with a boron-doped a-SiC:H buffer layer, have been shown to be somewhat less stable than cells produced with $\mathrm{H}_{2}-$ dilution [4]; however, they become again interesting in the context of micromorph cells due to their relatively high current levels. In order to provide as much current as possible for the micromorph cell, the top cell has to be quite thick, which affects in its turn the stability of the top cell.

We deposited thickness series of cells for two different i-layer materials. Each cell was, on the one hand, partly contacted as a single-junction cell and, on the other hand, partly used as the top cell in a micromorph tandem cell. The single-junction and the tandem cells were degraded in parallel under the same conditions (spectra close to AM1.5, $100 \mathrm{~mW} / \mathrm{cm}^{2}$, $\left.50^{\circ} \mathrm{C}, 1000 \mathrm{~h}\right)$. Fig.1. shows the results for these two series: A) i-layer material deposited without $\mathrm{H}_{2}$-dilution at standard substrate temperature of $220^{\circ} \mathrm{C}, \mathrm{E} 04 \approx 1.88$ $\mathrm{eV}$; B) cells deposited at $\mathrm{T}_{\mathrm{S}}=180^{\circ} \mathrm{C}$ from a $\mathrm{H}_{2}$-diluted plasma (dilution ratio 2), $\mathrm{E}_{04} \approx 1.92 \mathrm{eV}$. Both series contain a thin a-Si:H buffer layer with a dilution ratio of 9.

The stabilized efficiency values of the singlejunction cells (black symbols in Fig.1.) of both series are nearly independent of the i-layer thickness in the investigated range between 1500 and $3000 \AA$ (Fig.1d.). For both series, the increase of the short circuit current (Fig.1b.) with increasing i-layer thickness is counteracted by a decrease of the fill factor (Fig.1c.) resulting in a nearly constant degraded efficiency in the investigated thickness range. Efficiency values are somewhat higher for the diluted cells at lower deposition temperature (series B), this is due to higher $\mathrm{V}_{\text {Oc }}$ values (Fig.1a.) which overcompensate the slight loss in current. This loss in current is more pronounced for the tandem cells than for the single-junction cells (Fig.1b.), due to the missing back reflector in the tandem top cells.

While the situation is relatively clear for the case of

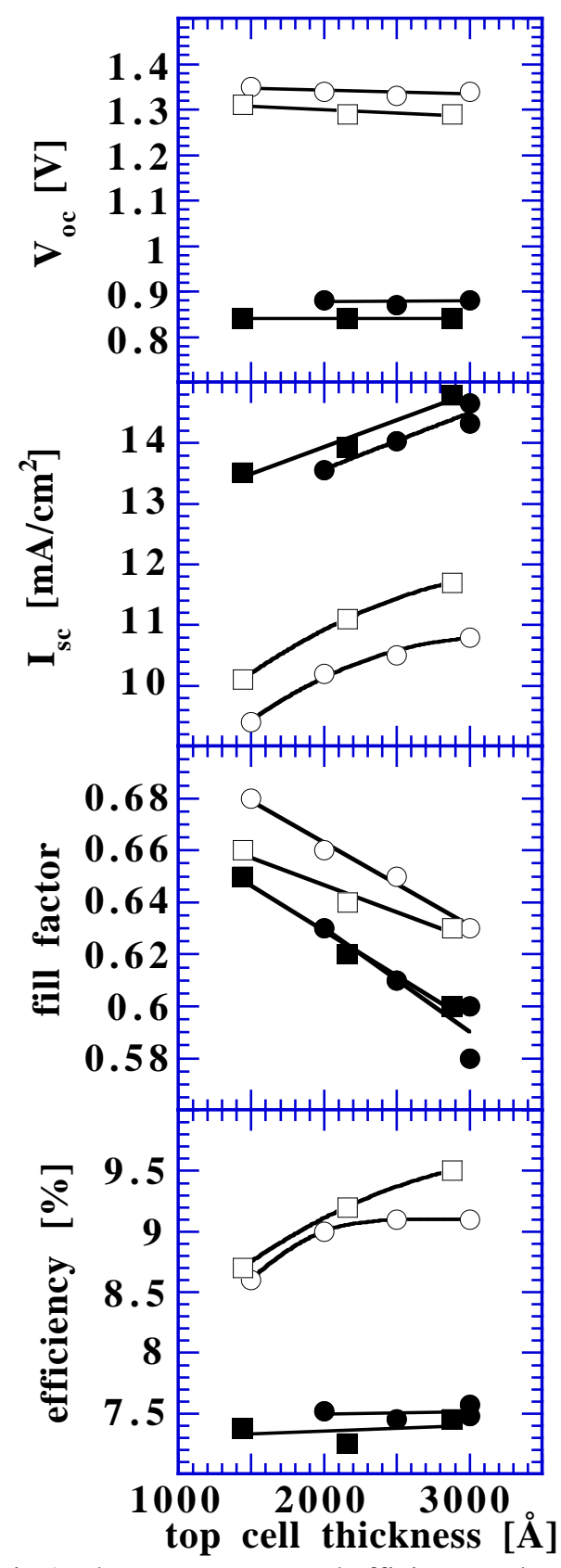

Fig.1a-d.: $\mathrm{V}_{\text {oc }}, \mathrm{I}_{\mathrm{Sc}}, \mathrm{FF}$ and efficiency values in the degraded state for the thickness series A) $\mathbf{\square}$ standard material without $\mathrm{H}_{2}$-dilution, $\mathrm{T}_{\mathrm{S}}=220^{\circ} \mathrm{C}$; B) : dilution $2, \mathrm{~T}_{\mathrm{S}}=180^{\circ} \mathrm{C}$. Filled symbols are for single cells and open symbols are for the corresponding tandem cells. single-junction cells (linear relationship between $\mathrm{V}_{\mathrm{Oc}}, \mathrm{I}_{\mathrm{Sc}}, \mathrm{FF}$ and efficiency), it becomes more complex in the case of micromorph tandem cells. In fact, we observe for series A a constant increase of the stabilized efficiency of the tandem cells with increasing top cell thickness, without reaching the maximum in the investigated thickness range. The current of the top cell and conclusively that of the micromorph cell increases with increasing cell thicknesses, the fill factor of the top cell decreases in the degraded state with increasing cell thickness. The continuous increase in efficiency for the tandem cell with the top cell thickness is due to the fact 
that, on the one hand, the degraded fill factor of the micromorph cell is found to decrease to a smaller extent with the thickness of the top cell than the fill factor of the single-junction cell (Fig.1c.); on the other hand, a gain of $1.6 \mathrm{~mA} / \mathrm{cm}^{2}\left(10.1 \mathrm{~mA} / \mathrm{cm}^{2}\right.$ at $1500 \AA$ and $11.7 \mathrm{~mA} / \mathrm{cm}^{2}$ at $3000 \AA$ for the tandem cell) means an increase of $+15.8 \%$ relative whereas a loss of 0.03 in FF $(66 \%$ at $1000 \AA$ and $63 \%$ at $3000 \AA)$ means only a loss of $-4.5 \%$ relative for the tandem cell.

The situation is quite similar for the diluted cells at lower substrate temperature (series B). The lower current density due to the enhanced optical gap of the top cell results directly in a lower efficiency of the micromorph tandem cell. The higher $\mathrm{V}_{\mathrm{Oc}}$ values of the single cells are directly transferred to the tandem cells, however this gain in $\mathrm{V}_{\mathrm{Oc}}$ cannot compensate the loss in current. We observe therefore overall lower efficiencies for the tandem cells of series B as compared to the tandem cells of series A. In both cases, series A and B, we observe a stabilized efficiency of the single cells which is independent of the cell thickness in the investigated thickness range, whereas the stabilized efficiency increases with top cell thickness for the corresponding tandem cells; the maximum will appear for even thicker top cell i-layers.

As a preliminary conclusion of these experimental results, one notes that the situations for single-junction cells and for micromorph tandem cells are different. Due to the high current of the micromorph bottom cell (up to $26 \mathrm{~mA} / \mathrm{cm}^{2}$ ) and its rather low voltage of about $0.45 \mathrm{~V}$, it is preferable to have a top cell which furnishes a high current rather than a high voltage. The optimum i-layer thickness for the top cell seems to be larger for micromorph cells than for single-junction or for a-Si:H/a-Si:H tandem cells: a somewhat lower FF of the top cell is not directly transferred to the micromorph cell. The cell with the highest degraded efficiency as single-junction cell is not identical with the cell that results in a micromorph tandem with the highest stabilized efficiency.

\section{WHICH BANDGAP AND THICKNESS FOR THE AMORPHOUS TOP CELL? The optical model}

Having recognized how important the short-circuit current of the top cell is for the stabilized efficiency of a micromorph tandem cell, we tried to figure out by means of a simple optical model which current values are basically available in such a top cell, in function of the i-layer thickness and of the optical gap of the ilayer. The model is straightforward: as input we take measured absorption curves $\alpha(h v)$ for "standard" a$\mathrm{Si}: \mathrm{H}$ and $\mu \mathrm{c}-\mathrm{Si}: \mathrm{H}$ [8]. In order to simulate different optical gaps of different a-Si:H layers, we simply shifted the $\alpha(h v)$ curve parallel on the $h v$-axis: this has shown to be a good approximation for the materials studied by us so far; we will use it as a working hypothesis for the whole range of hypothetical materials considered here. We give for the optical gap the $\mathrm{E}_{04}$ value. The currents in the top and bottom cells are calculated on the basis of the simple Lambert-Beer absorption law and taking into account the reflection at the front glass surface. The hazed $\mathrm{SnO}_{2}$ substrate (Asahi U) is taken into account by multiplying the ilayer thickness by a identical factor for all cells. As the bottom cell is strongly absorbing and very thick (2-3

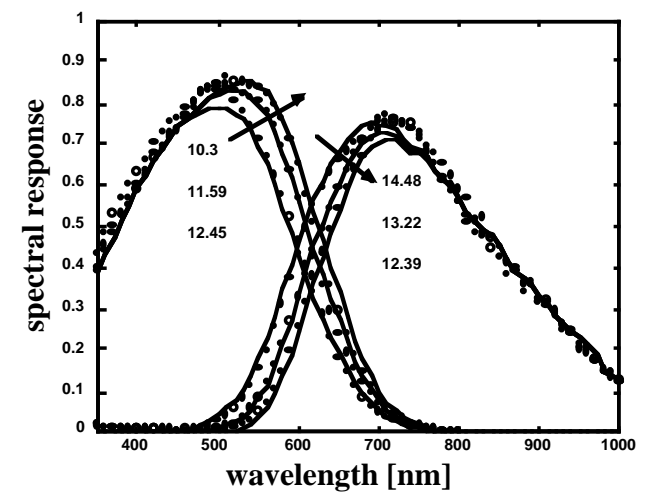

Fig.2.: Modeled spectral response curves of micromorph tandem cells (lines) and comparison to measured SR curves (points) for different i-layer thicknesses (1500, 2000, 2500 $\AA$ ) of the amorphous top cell. The top cell ilayer material is our "standard" undiluted material with an optical gap $\mathrm{E}_{04}=1.86 \mathrm{eV}$. Numbers indicate currents $\left(\mathrm{mA} / \mathrm{cm}^{2}\right)$ obtained by multiplying the calculated SR curves with an AM1.5 spectra.

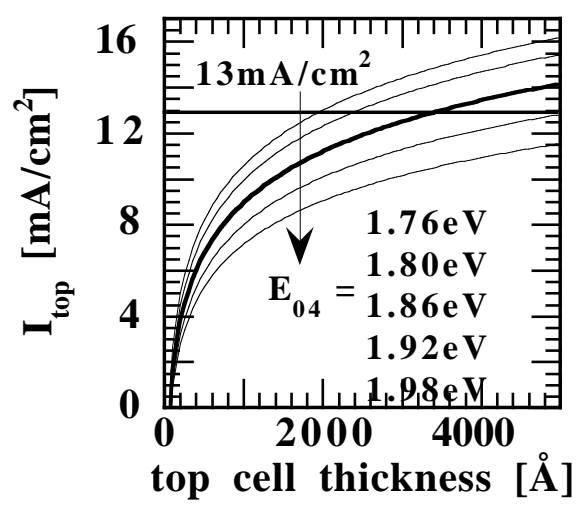

Fig.3.: Top cell currents for different optical gaps $\mathrm{E}_{04}$ and different i-layer thicknesses of the top cell, according to the optical simulation. $\mathrm{E}_{04}=1.86 \mathrm{eV}$ corresponds to our "standard" undiluted material. 
$\mu \mathrm{m})$, we neglect the light that is reflected at the back reflector and reaches the top cell again. The thickness of the bottom cell is again multiplied by a constant factor in order to take into account the enhancement of the optical path due to the back reflector. In spite of the simplicity of the model we observed a satisfying agreement between simulation and measured spectral response (SR) curves for all optical gaps and thicknesses of the top cells from the micromorph tandem which are available so far. Fig.2. shows, as an example, measured and calculated SR curves for $\mathrm{E}_{04}=1.86 \mathrm{eV}$ and for 3 different top cell thicknesses. Note that the sum of top and bottom cell current remains constant at $\approx 25 \mathrm{~mA} / \mathrm{cm}^{2}$.

Fig.3. shows the calculated top cell current as a function of the optical bandgap and of the thickness of the top cell i-layer. Note that these values are only valid for top cells without back reflector, or for those on top of a $\mu \mathrm{c}-\mathrm{Si}: \mathrm{H}$ bottom cell.

\section{The electrical model}

In order to calculate the efficiency of a micromorph tandem cell with a given top cell, one must also take into account the influence of the optical gap on the $\mathrm{V}_{\mathrm{Oc}}$ of the top cell as well as the influence of the top cell thickness on the degraded fill factor of the top cell and, finally, also of the tandem cell. Therefore we added to our optical model an electric part, i.e. a procedure to calculate the I-V curve of a tandem cell for different top cells.

The calculations are based on measured I-V curves of amorphous cells in different states of degradation (which are therefore showing different fill factors) and on the measured I-V curve of a typical $\mu \mathrm{c}-\mathrm{Si}: \mathrm{H}$ cell $\left(63 \% \mathrm{FF}\right.$ and $\left.\mathrm{V}_{\mathrm{Oc}}=0.49 \mathrm{~V}\right)$. We scaled the I-V curves of the top cells in order to obtain the desired $\mathrm{V}_{\mathrm{OC}}$ and current level. $\mathrm{V}_{\mathrm{OC}}$ values were estimated to depend linearly on the optical gap of the i-layer; this is a reasonable approximation as long as "secondary" effects, such as contamination or other problems [9], can be neglected. Based on measured $\mathrm{V}_{\mathrm{OC}}$ values of our cells with different bandgap energies, we extrapolated the $V_{\text {Oc }}$ values as shown on the bottom of Fig.4. The $\mathrm{V}_{\mathrm{Oc}}$ values are here assumed to be independent of the i-layer thickness.

Degraded fill factors were assumed to depend only on the thickness of the i-layer. The FFvalues employed are based on the measured values for degraded single-junction cells as shown in Fig.1. and extrapolated to larger thicknesses (Fig.4., right). This is a simplification as there may be some differences in stability for different i-layer materials, a fact that has to be kept in mind for the interpretation of the results. Note, that these are FF values which have been measured for single-junction cells. The fill factor in a tandem cell will degrade to a smaller extent than the FF in a single-junction cell which corresponds to the top cell, as the light intensity is smaller without the back reflector. Thus, the simulation underestimates the FF values of the top cells and simulated efficiencies will therefore be somewhat smaller than measured efficiencies for micromorph cells.

The currents were scaled according to the values obtained from the optical modeling for the top cell: the total cell current was held constant at $26 \mathrm{~mA} / \mathrm{cm}^{2}$, the top cell absorbs its part in function of its bandgap and thickness, as given in Fig.3.

After the scaling procedure we simply added the curves $\mathrm{V}_{\text {top }}(\mathrm{I})$ and $\mathrm{V}_{\text {bottom }}(\mathrm{I})$ in order to estimate the I-V curve of the micromorph tandem cell. Fig.4. shows the resulting efficiency values as a function of the top cell i-layer thickness and its optical bandgap. Increasing optical bandgap means increasing $\mathrm{V}_{\mathrm{Oc}}$, but decreasing current. Increasing i-layer thickness means increasing current but decreasing fill factor of the top cell. However, the top cell FF and the tandem cell FF depend in a strongly nonlinear manner on each other. The latter depends strongly on the current matching between the both component cells. It is obvious that the maximum of the efficiency is situated at lower bandgap energies for the top cell than those that we actually obtain with "standard" amorphous material, which is in fact the lowest gap we can obtain so far. If the bandgap energy becomes too small, the tandem cell becomes strongly "bottom-limited" which in turn results again in a decrease of the efficiency of the cell. At the same time, the $V_{\text {Oc }}$ of the top cell decreases which also reduces the tandem cell efficiency. Concerning the optimum thickness, it is evident that very thin top cells can by far not provide enough current to yield a good efficiency of the top cell. There is a broad maximum between 2000 and $3000 \AA$, depending on the bandgap of the top cell. For smaller bandgap energies of the top cell, the maximum shifts towards smaller cell thicknesses, as those cells can provide enough current with less cell 
thickness and also possess a better degraded fill factors than thicker cells. Towards very thick cells, the deterioration of the FF of the top cell and bottom limitation reduce once again the efficiency. Obviously, the numerical modeling underestimates efficiencies, as can be seen from the measured data points in Fig.4. 10.7\% stabilized efficiency have been independently measured at the FhG-ISE (Freiburg, Germany), the cell with $11.2 \%$ stabilized efficiency has been measured at our institute [3]. This is due to the underestimation of the FF of the top cell, already mentioned above.

The numerical modeling clearly shows that with our so far existing material, top cells with a thickness of 2500-3500 $\AA$ should yield micromorph tandem cells with the best performance; this fact is in agreement with the experimental results shown in this paper. Furthermore, in order to obtain even higher stabilized efficiencies for micromorph tandem cells, we should ideally have an amorphous ilayer material with an optical gap that is about 60-70 meV lower than our present "standard" material. Of course, this result of the numerical modeling is only valid provided this new material shows at least the same stability as the existing amorphous materials and if, furthermore, we can make cells with this material that have a $\mathrm{V}_{\mathrm{OC}}$ value that is merely reduced proportionally to its reduced optical bandgap.

\section{THE TANDEM CELL DESIGN FOR OPTIMUM STABILIZED OUTPUT POWER}

The numerical modeling presented above is based on choosing a top cell current corresponding to the optical gap and thickness of the top cell i-layer; the bottom cell current is taken as $26 \mathrm{~mA} / \mathrm{cm}^{2}$ - I top. Due to the obvious difficulty to obtain current matching with "conventional" amorphous top cells, all cells fabricated by us so far were more or less top-limited. However, it has been shown that the current matching has an influence on the stabilized efficiency of a-Si:H/a-Si:H stacked cells $[5,10]$. We therefore modeled the case of a top cell with a constant $\mathrm{V}_{\mathrm{OC}}$ and $\mathrm{FF}$, but a current varying over a wide range. Fig.5. shows the calculated efficiency of the micromorph tandem cell in the degraded state as a function of the top cell current for different total cell currents Itop+Ibottom. The efficiency is maximum for top cell currents slightly higher than

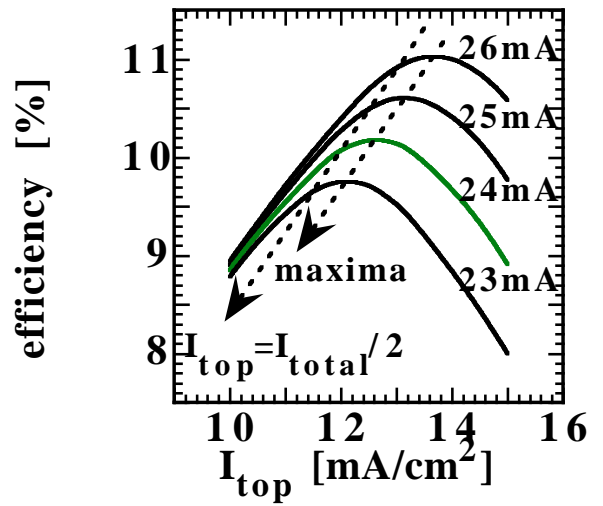

Fig.5.: Calculated efficiencies in function of the top cell current for different total cell currents. Fill factor and $\mathrm{V}_{\mathrm{Oc}}$ of the top cell are $66 \%$ and $0.89 \mathrm{~V}$ respectively, the bottom cell is the same as used above $(0.49 \mathrm{~V}, 63 \%$ FF). Arrowed lines indicate the points of current matching as well as the points of maximum efficiency of the tandem cell. 
Itotal $/ 2$, i.e. for bottom-limited conditions. Note that the situation is different for micromorph cells than for a-Si:H/a-Si:H stacked cells where we found a maximum after degradation for slightly top-limited conditions [5]. This is due to a pronounced difference in the two situations: in the case of amorphous stacked cells, power generation is comparable in both component cells due to comparable $\mathrm{V}_{\mathrm{Oc}}$ values. Both cells are subject to degradation. In the case of the micromorph tandem cell, only the top a-Si:H cell is subject to degradation and at the same time it provides $2 / 3$ of the output power due to its $\mathrm{V}_{\text {Oc }}$ which is about twice as high as that of the bottom $\mu \mathrm{c}-\mathrm{Si}: \mathrm{H}$ cell. Thus, in order to further increase the stabilized efficiency of micromorph tandem cells, it seems to be important to carefully adjust the current equilibrium between both the component cells. However, in order to be able to reach in practice the specially interesting bottom-limited conditions, the development of low gap amorphous material as described above is required.

\section{CONCLUSIONS}

The optimization problem of the top cell for a micromorph tandem cell is very different from the optimization of a single-junction or of an a-Si:H/a-Si:H stacked cell. Experimental results clearly show that the optimum thickness for an efficient micromorph top cell is larger than that for a single-junction cell. This is due to the reduced effect of FF degradation on the tandem cell performance as well as due to the importance of obtaining sufficient current for maximizing micromorph cell efficiency. Optimization should here rather be done in such a way as to obtain a higher current than in such a way as to enhance the $\mathrm{V}_{\text {Oc }}$. The above work has furthermore shown that the cell having the highest degraded efficiency as a single-junction cell is not the same as the cell which results in a micromorph tandem with the highest stabilized efficiency.

Semi-empirical modeling confirms the experimental results. A further optimization of the amorphous top cell has to go into the direction of a lowering of the bandgap of the i-layer material in order to generate more current in the top cell. For a total cell current of $26 \mathrm{~mA} / \mathrm{cm}^{2}$, the top cell should have a gap of about $\mathrm{E}_{04}=1.8 \mathrm{eV}$, i.e. remarkably lower than the "standard"

material obtained today. We have furthermore shown that the stabilized efficiency of a micromorph tandem cell is maximum for slightly bottom-limited conditions.

\section{ACKNOWLEDGMENTS}

Financial support by Swiss Federal Department of Energy BEW/OFEN, grants 2757 and 19431 is gratefully acknowledged.

\section{REFERENCES}

[1] J. Meier, R. Flückiger, H. Keppner and A. Shah, Appl. Phys. Lett. 65 (1994) 860.

[2] J. Meier, P. Torres, R. Platz, S. Dubail, U. Kroll, J.A. Anna Selvan, N. Pellaton Vaucher, C. Hof, D. Fischer, H. Keppner, A. Shah, K.-D. Ufert, P. Giannoulès, J. Koehler, MRS Symp. Proc. 420 (1996) 3.

[3] J. Meier, S. Dubail, R. Platz, P. Torres, U. Kroll, J.A. Anna Selvan, N. Pellaton Vaucher, C. Hof, D. Fischer, H. Keppner, R. Flückiger, A. Shah, V. Shklover, K.-D. Ufert, Proc. PVSEC-9, Miyazaki 1996, to be published.

[4] R. Platz, D. Fischer, C. Hof, S. Dubail, J. Meier, U. Kroll and A. Shah, MRS Symp. Proc. 420 (1996) 51.

[5] R. Platz, D. Fischer, S. Dubail and A. Shah, Solar Energy Materials and Solar Cells, to be published.

[6] S. Guha, Proc. 25th IEEE PVSC (1996) 1017.

[7] B. Rech, S. Wieder, F. Siebke, C. Beneking and H. Wagner, MRS Symp. Proc. 420 (1996) 33.

[8] N. Beck, J. Meier, J. Fric, Z. Remes, A. Poruba, R. Flückiger, J. Pohl, A. Shah, M. Vanecek, J. Non-Cryst. Solids 198-200 (1996) 903.

[9] M. Nishikuni, T. Takahama, S. Okamoto, K. Ninomiya, H. Nishiwaki, S. Tsuda, A. Takeoka, M. Ohnishi, S. Nakano and Y. Kuwano, Progr. in Photovoltaics 2 (1994) 211.

[10] X. Xu, J.C. Yang and S. Guha, Proc. 23rd IEEE PVSC (1993) 971. 